\title{
Validation of a dynamic simulation program according to EN ISO 15265
}

\author{
Magdalena Grudzińska ${ }^{1, *}$ \\ ${ }^{1}$ Lublin University of Technology, Faculty of Civil Engineering and Architecture, st. Nadbystrzycka 40, \\ 20-618 Lublin, Poland
}

\begin{abstract}
EN ISO 15265 is a standard describing validation procedures concerning dynamic simulation programs for evaluation of energy demand in buildings. The validation procedure comprises 12 tests altogether: 4 introductory ones and 8 proper validation tests differing with the assumptions concerning the partition construction, the thermal mass, window shading, external gains and functioning of the installation systems. Some procedures, for instance the calculation of solar radiation incident on the vertical planes, are not clearly described in the standard. The paper presents the discussion of possible interpretations of the procedures included in the standard and the results of validation of a simulation program based on the control volume method.
\end{abstract}

\section{Introduction}

Since the very beginning of the development of calculation methods concerned with the building physics the necessity of verification of the results obtained was clearly seen [1]. Validation of a computer program or calculation method is defined as a complex process of testing comprising of the control of its theoretical assumptions, practical applications and correct employment by the user [2].

One of the validation methods is a comparative analysis which consists of comparing the results obtained by means of various programs or various types of calculation methodology with respect to the analogous model and the input data. This kind of research allows for the testing of a lot of parameters and it is relatively cheap [3, 4].

In the European Union countries the comparative validation was comprised in the EN 15265 standard: "Energetic usage properties of buildings. Calculation of energy demand for heating and cooling the accommodation using dynamic methods. General criteria and validation procedures" [5] (which possesses the status of Polish Standard), EN ISO 13791 "Thermal usage properties of buildings. Calculation of inner temperature in summer without mechanical cooling. Simplified methods" [6] and 13792 "Thermal performance of buildings. Calculation of internal temperatures of a room in summer without mechanical cooling. Simplified methods" [7]. The standards are designed for calculation procedures which assume the time step as one hour or less without imposing at the same time a specified technique of calculation. The current article presents the validation results carried out for the BSim computer program (based on the method of control volumes).

*Corresponding author: m.grudzinska@pollub.pl 


\section{Validation procedures according to EN 15265}

The above standard comprises a set of assumptions, demands and validation research used for the calculation of heating and cooling demand in a given room. The research is carried out for a simple, one-zone room with a single window in the outer wall in operating conditions of the outer climate. The procedure comprises 12 tests altogether: 4 introductory ones and 8 proper validation tests differing with the assumptions concerning the partition construction, the thermal mass, window shading, external gains and functioning of the installation systems. The attempts at using the standard method for validation of dynamic simulation programs are presented in publications included in the literature of the subject $[8,9,10]$.

Validation applies to calculation procedures comprising [5]:

- the thermal balance of the external and internal surfaces,

- the thermal balance of the external and internal partitions,

- the thermal balance of the air.

The control room has the following dimensions: it is $3.6 \mathrm{~m}$ long, $5.5 \mathrm{~m}$ wide and $2.8 \mathrm{~m}$ high. In the external wall facing west there is a double-glazed window of $7.0 \mathrm{~m}^{2}$. Climatic conditions during one year are characterized by the hourly values of the outside air and the intensity of beam and diffuse solar radiation.

Table 1. Thermophysical properties of the room components according to [5].

\begin{tabular}{|c|c|c|}
\hline Partition & Description & $\begin{array}{c}\text { Thermal } \\
\text { transmittance } \\
\text { coefficient } U \\
{\left[\mathbf{W} / \mathbf{m}^{2} \mathbf{K}\right]}\end{array}$ \\
\hline Type 1 (external wall) & $\begin{array}{c}\text { Outer layer } 0.115 \mathrm{~m} \\
\text { Insulating layer } 0.060 \mathrm{~m} \\
\text { Masonry } 0.175 \mathrm{~m} \\
\text { Internal plastering } 0.015 \mathrm{~m}\end{array}$ & 0.373 \\
\hline Type 2 (internal wall) & $\begin{array}{c}\text { Gypsum plaster } 0.012 \mathrm{~m} \\
\text { Mineral wool } 0.100 \mathrm{~m} \\
\text { Gypsum plaster } 0.012 \mathrm{~m}\end{array}$ & 0.265 \\
\hline $\begin{array}{l}\text { Type } 3 \mathrm{c} \text { or } 3 \mathrm{f} \\
\text { (ceiling or floor) }\end{array}$ & $\begin{array}{c}\text { Plastic covering } 0.004 \mathrm{~m} \\
\text { Cement floor } 0.060 \mathrm{~m} \\
\text { Mineral wool } 0.040 \mathrm{~m} \\
\text { Concrete } 0.180 \mathrm{~m}\end{array}$ & $\begin{array}{c}0.474 \text { (ceiling) } \\
0.299 \text { (floor) }\end{array}$ \\
\hline $\begin{array}{l}\text { Type } 4 \mathrm{c} \text { or } 4 \mathrm{f} \\
\text { (ceiling or floor) }\end{array}$ & $\begin{array}{c}\text { Plastic covering } 0.004 \mathrm{~m} \\
\text { Cement floor } 0.060 \mathrm{~m} \\
\text { Mineral wool } 0.040 \mathrm{~m} \\
\text { Concrete } 0.180 \mathrm{~m} \\
\text { Mineral wool } 0.100 \mathrm{~m} \\
\text { Acoustic board } 0.020 \mathrm{~m}\end{array}$ & $\begin{array}{c}0.202 \text { (ceiling) } \\
0.162 \text { (floor) }\end{array}$ \\
\hline Type 5 (roof) & $\begin{array}{c}\text { Rain protection } 0.004 \mathrm{~m} \\
\text { Insulation } 0.080 \mathrm{~m} \\
\text { Concrete } 0.200 \mathrm{~m} \\
\end{array}$ & 0.366 \\
\hline Window & $\begin{array}{l}\text { Double glazing without shading, } \mathrm{g}=0.77 \\
\text { Double glazing with shading, } \mathrm{g}=0.20\end{array}$ & $\begin{array}{l}2.930 \text { (glazing) } \\
2.370 \text { (glazing) }\end{array}$ \\
\hline
\end{tabular}




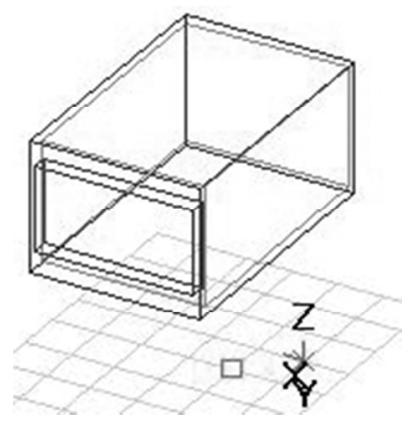

Fig. 1. Test room according to EN 15265, sketch from the BSim program.

A detailed material description containing heat conductivity and heat capacity as well as optical properties of glazing is included in [5]. The standard also presents the detailed coefficients of heat transfer through convection and radiation at the particular partition surfaces. Within the room the assumed internal gains are about $20 \mathrm{~W} / \mathrm{m}^{2}$, one air exchange per hour, as well as temperature setting for the heating and cooling mode respectively: $20^{\circ} \mathrm{C}$ and $26^{\circ} \mathrm{C}$.

The validation research comprises 4 introductory tests and 8 main tests carried out with the assumption of varied heat capacity of a room, various internal gains and the option of closing or opening the curtains (Table 2). The introductory research is not obligatory but it may be used in order to carry out a preliminary control of the calculation method.

Table 2. Test cases according to [5].

\begin{tabular}{|c|c|c|c|c|c|c|}
\hline No. & $\begin{array}{c}\text { External } \\
\text { wall }\end{array}$ & Glazing & $\begin{array}{c}\text { Ceiling/ } \\
\text { Roof }\end{array}$ & Floor & $\begin{array}{l}\text { Heating and } \\
\text { cooling }\end{array}$ & Description \\
\hline 1. & Type 1 & Shaded & Type 4c & Type $4 f$ & Continuous & Internal gains \\
\hline 2. & Type 1 & Shaded & Type 3c & Type 3f & Continuous & Change of inertia \\
\hline 3. & Type 1 & Shaded & Type 4c & Type 4f & Continuous & No internal gains \\
\hline 4. & Type 1 & Not shaded & Type 4c & Type 4f & Continuous & No solar shading \\
\hline 5. & Type 1 & Shaded & Type 4c & Type 4f & Intermittent & Internal gains \\
\hline 6. & Type 1 & Shaded & Type 3c & Type 3f & Intermittent & Change of inertia \\
\hline 7. & Type 1 & Shaded & Type 4c & Type 4f & Intermittent & No internal gains \\
\hline 8. & Type 1 & Not shaded & Type 4c & Type 4f & Intermittent & No solar shading \\
\hline 9. & Type 1 & Shaded & Type 5 & Type $4 \mathrm{f}$ & Intermittent & Internal gains \\
\hline 10. & Type 1 & Shaded & Type 4c & Type $3 \mathrm{f}$ & Intermittent & Change of inertia \\
\hline 11. & Type 1 & Shaded & Type 5 & Type $4 \mathrm{f}$ & Intermittent & No internal gains \\
\hline 12. & Type 1 & Not shaded & Type 5 & Type $4 \mathrm{f}$ & Intermittent & No solar shading \\
\hline
\end{tabular}

The results, i.e. the heat and cold demand are compared with the reference values presented in the Table 3. 
Table 3. Reference results - energy demand for heating $\left(\mathrm{Q}_{\mathrm{H}, \mathrm{ref}}\right)$ and cooling $\left(\mathrm{Q}_{\mathrm{C}, \mathrm{ref}}\right)$.

\begin{tabular}{|c|c|c|c|}
\hline No. & $\begin{array}{c}\mathbf{Q}_{\mathbf{H , r e f}} \\
{[\mathbf{k W h}]}\end{array}$ & $\begin{array}{c}\mathbf{Q}_{\mathbf{C}, \text { ref }} \\
{[\mathbf{k W h}]}\end{array}$ & $\begin{array}{c}\mathbf{Q}_{\text {tot,ref }} \\
{[\mathbf{k W h}]}\end{array}$ \\
\hline 1. & 748.0 & 233.8 & 981.8 \\
\hline 2. & 722.7 & 200.5 & 923.2 \\
\hline 3. & 1368.5 & 43.0 & 1411.6 \\
\hline 4. & 567.4 & 1530.9 & 2098.3 \\
\hline 5. & 461.3 & 201.7 & 664.8 \\
\hline 6. & 509.8 & 185.1 & 694.9 \\
\hline 7. & 1067.4 & 19.5 & 1086.9 \\
\hline 8. & 313.2 & 1133.2 & 1446.4 \\
\hline 9. & 747.1 & 158.3 & 905.4 \\
\hline 10. & 574.2 & 192.4 & 766.6 \\
\hline 11. & 1395.1 & 14.1 & 1409.3 \\
\hline 12. & 533.5 & 928.3 & 1461.8 \\
\hline
\end{tabular}

Dependent on the differences between the determined quantities and the reference ones, the calculation method may be qualified as a method at the accuracy level A, B or C where the absolute error is respectively $5 \%, 10 \%$ or $15 \%$ (the decisive is the worst case).

$$
\begin{aligned}
& r_{Q H}=\frac{\left|Q_{H}-Q_{H, r e f}\right|}{Q_{t o t, r e f}} \\
& r_{Q C}=\frac{\left|Q_{C}-Q_{C, r e f}\right|}{Q_{\text {tot }, \text { ref }}}
\end{aligned}
$$

- for the level A: $\mathrm{r}_{\mathrm{QH}} \leq 0.05$ and $\mathrm{r}_{\mathrm{QC}} \leq 0.05$,

- for the level B: $\mathrm{r}_{\mathrm{QH}} \leq 0.10$ and $\mathrm{r}_{\mathrm{QC}} \leq 0.10$,

- for the level C: $\mathrm{r}_{\mathrm{QH}} \leq 0.15$ and $\mathrm{r}_{\mathrm{QC}} \leq 0.15$.

\section{Solar radiation distribution}

In spite of the minutely defined partitions and the functioning of the installation systems the data included in the standard reveal certain gaps. There is no information concerning the type of window frames, ground reflectivity or the way of determining the intensity of solar radiation upon the vertical surfaces. The annex to the standard [5] quotes the quantities of beam and diffuse radiation falling upon the horizontal surface as well as the intensity of the total radiation on the vertical surface facing west (with a window in it). However, it has not been determined whether the quantities of radiation falling upon the surface have been obtained by means of measurement or determined by way of analysis (or what kind of mathematical models have been used for the purpose). Dynamic simulation programs usually use standard measurement data, such as solar radiation on a horizontal plane, and converse it into radiation falling on sloped surfaces. Taking into account the fact that the BSim program gives an opportunity to calculate the intensity of solar radiation reaching vertical surfaces in several ways, the first stage of validation consisted in comparing the results obtained through the use of particular models with the data presented in the standard. 
The intensity of solar radiation falling upon the inclined surface $I_{\beta}$ is the sum of beam radiation $\mathrm{I}_{\mathrm{b}, \beta}$ (coming directly from the solar disc), diffuse radiation coming from the sky $I_{d, \beta}$ and reflected from the ground surface $I_{r, \beta}$ :

$$
I_{\beta}=I_{b, \beta}+I_{d, \beta}+I_{r, \beta}
$$

If we know the intensity of beam radiation at the horizontal surface and the geometrical dependencies determining the position of the sun, we can calculate the directional component of radiation upon the surface inclined at $\beta$ angle employing Hottel-Wortz's method [11-13]:

$$
I_{b, \beta}=I_{b} \frac{\cos \theta}{\cos \theta_{z}}
$$

where:

$I_{b, \beta}$ - intensity of beam radiation falling at the inclined surface at $\beta$ angle to the horizontal surface $\left[\mathrm{W} / \mathrm{m}^{2}\right]$

$\mathrm{I}_{\mathrm{b}}$ - intensity of beam radiation falling upon the horizontal surface $\left[\mathrm{W} / \mathrm{m}^{2}\right]$

$\theta$ - the angle of incidence between the beam radiation and the inclined surface (measured with respect to the normal to this surface)

$\theta_{z}$ - the angle of incidence of beam radiation upon the horizontal surface (measured with respect to the normal to this surface).

Diffuse radiation reaching the inclined surface from the sky is more difficult to estimate because of the anisotropic character. If the sky is clear, the intensity of diffuse radiation is bigger around the solar disc and over the horizon. The more cloudy it is, the more the pattern of diffuse radiation intensity approaches the regular one at the whole expanse of the sky.

The earliest, in the historical sense, models of intensity calculation of the diffuse radiation reaching the inclined surface are isotropic models assuming its regular pattern at the whole expanse of the sky. The best known model in this group is the one by Liu and Jordan [14] made in the 60's of the previous century, according to which the intensity of diffuse radiation is calculated as:

$$
I_{d, \beta}=I_{d} \frac{1+\cos \beta}{2}
$$

where:

$I_{d, \beta}$ - intensity of diffuse radiation falling at the inclined surface at $\beta$ angle to the horizontal surface $\left[\mathrm{W} / \mathrm{m}^{2}\right]$,

$I_{d}$ - intensity of diffuse radiation falling at the horizontal surface $\left[\mathrm{W} / \mathrm{m}^{2}\right]$.

On the basis of isotropic models a series of pseudo-isotropic models was produced during 70's and 80's introducing slight mathematical corrections into the equations increasing the calculation accuracy. The group includes the models of Temps-Coulson [15], Klucher [16] and Hay [17]. The third group includes anisotropic models taking into account radiation non-uniformity through the isolation and exact calculation of their two or three components (circumsolar radiation, radiation over the horizon and the one coming from the remaining part of the sky). The most popular among the anisotropic models are the ones by Gueymard [18], Muneer [19, 20] and Perez [21-23].

In the BSim program the component of the diffuse radiation reaching the inclined surfaces may be determined among others by means of Lund's isotropic model and the anisotropic models of Muneer and Perez. Their basic assumptions are presented below.

The model by Lund treats the actual conditions as a superposition of the state of the sky completely clouded and quite clear based on the following dependencies [24]: 


$$
I_{d, \beta}=\frac{f_{o c} \cdot 1.5 N+f_{c l}(8-N)}{0.5 N+8} I_{d}
$$

where:

$\mathrm{f}_{\mathrm{oc}}$ - the coefficient taking into account the share of radiation coming from the fully overcast sky,

$\mathrm{f}_{\mathrm{cl}}$ - the coefficient taking into account the share of radiation coming from a clear sky,

$\mathrm{N}$ - the degree of cloudiness (from 0 to 8 where 0 designates a clear sky while $8-$ a fully overcast one).

The $f_{o c}$ and $f_{c l}$ coefficients are determined on the basis of empirical dependencies, given in the function of angle $\theta$ which is the angle of incidence of beam radiation at the inclined surface (measured with respect to the normal to this surface).

If $\cos \theta<0$ :

$$
\begin{gathered}
f_{o c}=\left(0.42+0.6 \cdot \cos \theta \frac{8-N}{8}\right) \cdot(1-\cos \beta)+\cos \beta \\
f_{c l}=(0.65+0.1 \cdot \cos \theta) \cdot(1-\cos \beta)+\cos \beta
\end{gathered}
$$

if $\cos \theta \geq 0$ :

$$
\begin{gathered}
f_{o c}=0.42 \cdot(1-\cos \beta)+\cos \beta \\
f_{c l}=\left(0.65+0.2 \cdot \cos \theta+0.45 \cos ^{2} \theta\right) \cdot(1-\cos \beta)+\cos \beta
\end{gathered}
$$

Muneer's model [19] considers separately the directly irradiated and shaded surfaces. In the conditions of overcast sky, the main equation for both types of surfaces is as follows:

$$
I_{d, \beta}=I_{d}\left[\cos ^{2} \frac{\beta}{2}+\frac{2 b}{\pi(3+2 b)} \cdot\left(\sin \beta-\beta \cos \beta-\pi \sin ^{2} \frac{\beta}{2}\right)\right]
$$

and for the directly irradiated surfaces in the conditions of clear sky:

$$
I_{d, \beta}=I_{d}\left[\cos ^{2} \frac{\beta}{2}+\frac{2 b}{\pi(3+2 b)} \cdot\left(\sin \beta-\beta \cos \beta-\pi \sin ^{2} \frac{\beta}{2}\right)\right] \cdot(1-F)+I_{d} \cdot F \frac{\cos \theta}{\cos \theta_{z}}(1
$$

where:

$\mathrm{b}$ - is the quotient assuming a constant quantity (equal 2.5) in the equation (11) and in the equation (12) calculated as:

$$
\frac{2 b}{\pi(3+2 b)}=0.04-0.82 F-2.026 F^{2}
$$

F - sky clarity index:

$$
F=\frac{I_{b}}{I_{0}}
$$

$\mathrm{I}_{\mathrm{b}}$ - intensity of beam radiation falling upon the horizontal surface $\left[\mathrm{W} / \mathrm{m}^{2}\right]$, $\mathrm{I}_{0}$ - the intensity of radiation outside the Earth's atmosphere upon the surface parallel to the considered horizontal surface $\left[\mathrm{W} / \mathrm{m}^{2}\right]$. 
The first versions of the model made by Perez were presented in publications [21, 22]. Its latest version that is presented in the current paper was developed and presented in [23]. In order to determine diffuse radiation intensity upon the surface inclined to the horizontal surface at an arbitrary angle B the following dependency is used:

$$
I_{d, \beta}=I_{d} \cdot\left[\left(1-F_{1}\right) \frac{1+\cos \beta}{2}+F_{1} \frac{a}{b}+F_{2} \sin \beta\right]
$$

where:

$I_{d, \beta}$ - intensity of diffuse radiation falling at the inclined surface at $\beta$ angle to the horizontal surface $\left[\mathrm{W} / \mathrm{m}^{2}\right]$,

$I_{d}$ - intensity of diffuse radiation falling at the horizontal surface $\left[\mathrm{W} / \mathrm{m}^{2}\right]$,

$\mathrm{a}, \mathrm{b}$ - the coefficients taking into account the angle of incidence of diffuse radiation from the circumsolar area and the inclined and horizontal surfaces:

$$
\begin{gathered}
a=\max (0 ; \cos \theta) \\
b=\max (0.087 ; \cos Z)
\end{gathered}
$$

$\mathrm{Z}$ - the zenith angle of the Sun,

$F_{1}, F_{2}$ - the coefficients of the sky expanse brightness in the circumsolar area and over the horizon dependent upon the zenith angle $\mathrm{Z}$, sky clearness $\varepsilon$ and sky brightness $\Delta$ of the atmosphere:

$$
\begin{gathered}
F_{1}=F_{11}+F_{12} \cdot \Delta+F_{13} \cdot Z \\
F_{2}=F_{21}+F_{22} \cdot \Delta+F_{23} \cdot Z \\
\Delta=\frac{I_{d} \cdot m}{I_{0}} \\
\varepsilon=\left(\frac{I_{d}+I_{b, n}}{I_{d}}+\kappa \cdot Z^{3}\right) /\left(1+\kappa \cdot Z^{3}\right)
\end{gathered}
$$

$\mathrm{m}$ - the optical mass of the atmosphere,

$\mathrm{I}_{0}$ - radiation intensity outside the Earth's atmosphere at the surface parallel to horizontal, $\mathrm{I}_{\mathrm{b}, \mathrm{n}}$ - intensity of beam radiation falling upon the normal surface $\left[\mathrm{W} / \mathrm{m}^{2}\right]$, $\kappa$ - a constant value equal to 1.041 for $\mathrm{Z}$ measured in radians.

The $F_{11}$ to $F_{23}$ coefficients for the particular ranges of atmosphere clarity are quoted in the paper [23].

Radiation reflected from the surface surrounding the analysed plane is treated as the isotropic diffuse radiation, determined by the formula [11-13]:

$$
I_{r, \beta}=\left(I_{b}+I_{d}\right) \cdot \rho_{g} \cdot \frac{1-\cos \beta}{2}
$$

where:

$\rho_{\mathrm{g}}$ - reflectivity of the surrounding surface.

The yearly course of the intensity of solar radiation reaching the vertical surface facing west determined by means of the models prepared by Lund, Muneer and Perez (for the ground reflectivity 0.2) was compared with the quantities included in the standard [5]. 
The results were estimated from the point of view of statistics calculating the mean bias error (MBE), the root mean squared error (RMSE), the mean absolute percentage error (MAPE) and the correlation coefficient (Table 4).

Table 4. Statistical analysis of the global solar radiation on a vertical, west facing wall according to the standard and the presented models.

\begin{tabular}{|c|c|c|c|c|}
\hline Model & $\begin{array}{c}\text { MBE } \\
\text { [\%] }\end{array}$ & $\begin{array}{c}\text { RMSE } \\
\text { [\%] }\end{array}$ & $\begin{array}{c}\text { MAPE } \\
{[\%]}\end{array}$ & $\begin{array}{c}\text { Correlation } \\
\text { coefficient [-] }\end{array}$ \\
\hline Lund & 19.97 & 38.27 & 3.10 & 0.97 \\
\hline Muneer & 34.46 & 47.35 & 10.54 & 0.94 \\
\hline Perez & 37.26 & 47.73 & 9.54 & 0.94 \\
\hline
\end{tabular}

The statistical analysis points to Lund's model as the closest to those presented in the standard. It can be proved by the smallest error values and the biggest correlation coefficient. It does not mean that Lund's model is the best one to map the intensity of radiation reaching the vertical surface, but only that it is the closest one to the data quoted by the standard, because, as it was already mentioned earlier, the standard [5] does not precisely state whether the data result from the measurements or they are determined by means of an analysis. Thus, the proper validation was based on the model prepared by Lund in order to estimate heating and cooling demand in the test chamber.

\section{Results of the validation tests}

Heating and cooling demand obtained for the particular validation tests was presented in the Table 5 .

Table 5. Reference demand for heating $\left(\mathrm{Q}_{\mathrm{H}, \mathrm{ref}}\right)$ and cooling $\left(\mathrm{Q}_{\mathrm{C}, \text { ref }}\right)$ and the results from BSim program (accordingly $\mathrm{Q}_{\mathrm{H}}$ and $\mathrm{Q}_{\mathrm{C}}$ ).

\begin{tabular}{|c|c|c|c|c|c|c|c|c|}
\hline No. & $\begin{array}{c}\mathbf{Q}_{\mathbf{H}, \text { ref }} \\
{[\mathbf{k W h}]}\end{array}$ & $\begin{array}{c}\mathbf{Q}_{\mathbf{C}, \text { ref }} \\
{[\mathbf{k W h}]}\end{array}$ & $\begin{array}{c}\mathbf{Q}_{\text {tot,ref }} \\
{[\mathbf{k W h}]}\end{array}$ & $\begin{array}{c}\mathbf{Q}_{\mathbf{H}} \\
{[\mathbf{k W h}]}\end{array}$ & $\begin{array}{c}\mathbf{Q}_{\mathbf{C}} \\
{[\mathbf{k W h}]}\end{array}$ & $\begin{array}{c}\mathbf{r}_{\mathbf{Q H}} \\
{[-]}\end{array}$ & $\begin{array}{c}\mathbf{r}_{\mathbf{Q C}} \\
{[-]}\end{array}$ & Category \\
\hline 1. & 748.0 & 233.8 & 981.8 & 902.3 & 255.1 & 0.16 & 0.02 & $-/ \mathrm{A}$ \\
\hline 2. & 722.7 & 200.5 & 923.2 & 865.3 & 204.4 & 0.15 & 0.00 & $\mathrm{C} / \mathrm{A}$ \\
\hline 3. & 1368.5 & 43.0 & 1411.6 & 1513.8 & 45.8 & 0.10 & 0.00 & $\mathrm{~B} / \mathrm{A}$ \\
\hline 4. & 567.4 & 1530.9 & 2098.3 & 858.2 & 1434 & 0.14 & 0.05 & $\mathrm{C} / \mathrm{A}$ \\
\hline 5. & 461.3 & 201.7 & 664.8 & 487.1 & 219.5 & 0.04 & 0.03 & $\mathrm{~A} / \mathrm{A}$ \\
\hline 6. & 509.8 & 185.1 & 694.9 & 600.1 & 188.6 & 0.13 & 0.01 & $\mathrm{C} / \mathrm{A}$ \\
\hline 7. & 1067.4 & 19.5 & 1086.9 & 1078.4 & 17.2 & 0.01 & 0.00 & $\mathrm{~A} / \mathrm{A}$ \\
\hline 8. & 313.2 & 1133.2 & 1446.4 & 382.2 & 111.8 & 0.05 & 0.01 & $\mathrm{~A} / \mathrm{A}$ \\
\hline 9. & 747.1 & 158.3 & 905.4 & 632.0 & 77.0 & 0.13 & 0.09 & $\mathrm{C} / \mathrm{B}$ \\
\hline 10. & 574.2 & 192.4 & 766.6 & 508.9 & 133.2 & 0.09 & 0.08 & $\mathrm{~B} / \mathrm{B}$ \\
\hline 11. & 1395.1 & 14.1 & 1409.3 & 1121.8 & 1.8 & 0.19 & 0.01 & $-/ \mathrm{A}$ \\
\hline 12. & 533.5 & 928.3 & 1461.8 & 554.4 & 754.4 & 0.01 & 0.12 & $\mathrm{~A} / \mathrm{C}$ \\
\hline
\end{tabular}

The best compatibility of the results and the referential data was obtained for the tests $5 \div 8$ for which a special room is modelled adjacent to the rooms of similar character (the lateral partitions and the ceiling are adiabatic partitions apart from the external wall facing west). Apart from one case, that is the heating demand in the room of altered heat capacity, the results may be included in the A category. The tests $9 \div 12$ in which the 
partition forming the upper limit of the room has contact with the outside air are slightly worse and the results - on average - can be included in the B category (apart from one case, i.e. the heating demand in test 11). In these tests it was necessary to take into account additionally the heat exchange by radiation during the summer season in order to obtain a good compatibility of the cooling demand with the reference results. In the primary tests $1 \div 4$ one can observe a much better accommodation to the cooling demand (A category in all tasks) than heating demand, as in the first task the permissible deviations were slightly exceeded. Generally, one can observe a tendency for a better mapping of energy demand in the summer season, but it was also in the winter season that category A was obtained in half of the obligatory examinations. There may be some problems with modelling rooms with big surfaces which are losing heat to the sky or of partitions with weaker isolation, but due to the conscious use of the program, in those situations it is possible to obtain credible results as well.

\section{Summary}

Validation of the simulation is an important stage of the work concerned with modelling the heat balance and energy demand in a building. It allows the control of adequacy of the assumptions and avoiding the so-called external errors, concerned with the inadequate preparation of the model by the user and isolation of the internal errors, related, among others, to the source code of the program. Validation also allows gaining greater experience and increasing the credibility of the person who makes simulations.

Checking the simulation computer programs with one-hour time step is relatively rare to be carried out in Poland. Experimental validation which consists in comparing the results with the quantities measured in an actual model is rather expensive and labour-consuming as it implies construction of a test stand functioning in real climatic condition as well as a very detailed measurement range. An alternative solution for those really advanced procedures may be comparative validation described in the current paper and carried out on the basis of the commonly available standards.

This work was financially supported by Ministry of Science and Higher Education in Poland, within the statutory research number S/14/2018.

\section{References}

1. K.J. Lomas, H. Eppel, C.J. Martin, D.P. Bloomfield, Energ. Buildings 26, 253 (1997)

2. S.Ø. Jensen, Energ. Buildings 22, 133 (1995)

3. M.C. Kersken, I. Heusler, P. Strachan: Full scale empirical validation for building energy simulation programs, 9th International Conference on System Simulation in Buildings, Liege, December 2014: https://www.researchgate.net/publication/ /280013681 (access 11.04.2017)

4. R. Judkoff, D. Wortman, B. O’Doherty, J. Burch: A methodology for validating building energy analysis simulations (National Renewable Energy Laboratory, Technical Report NREL/TP-550-42059, 2008)

5. EN 15265:2011 Thermal performance of buildings. Calculation of energy needs for space heating and cooling using dynamic methods. General criteria and validation procedures (European Committee for Standarization, Brussels, 2011)

6. EN ISO 13791 Thermal performance of buildings. Calculation of internal temperatures of a room in summer without mechanical cooling. General criteria and validation procedures (European Committee for Standarization, Brussels, 2012) 
7. EN ISO 13792 Thermal performance of buildings. Calculation of internal temperatures of a room in summer without mechanical cooling. Simplified methods (European Committee for Standarization, Brussels, 2012)

8. Validation of IDA Indoor Climate and Energy 4.0 with respect to CEN Standards EN 15255:2007 and EN 15265:2007 (Technical Report, EQUA Simulation, 2010).

9. Presentation from EN 15265:2007 with VIP-Energy version 3: www.vipenergy.net/Presentation_from_EN15265.pdf (access 19.05.2017)

10. DesignBuilder v4.5-EN 15265/ISO 13790 Validation Report: www.designbuilderitalia.it/wp-content/uploads/2015/05/Designbuilder-v4-5_EN15265_ISO-13790-Validation-Report.pdf (access 19.05.2017)

11. H.C. Hottel, B.B. Woertz, Trans ASME 64, 91 (1942)

12. J.F. Orgill, K.G.T. Hollands, Sol. Energy 19, 357 (1977)

13. D.T. Reindl, W.A. Beckman, J.A. Duffie, Sol. Energy 45, 1 (1990)

14. B.H.Y. Liu, R.C. Jordan, Sol. Energy 7, 53 (1963)

15. R.C. Temps, K.L. Coulson, Sol. Energy 19, 179 (1977)

16. T.M. Klucher, Sol. Energy 23, 111 (1979)

17. J.E. Hay, Sol. Energy 23, 301 (1979)

18. C.A. Gueymard: An anisotropic solar irradiance model for tilted surfaces and its comparison with selected engineering algorithms. Sol Energy 38, 367 (1987)

19. T. Muneer: Solar Radiation and Daylight Models, (Elsevier Butterworth-Heinemann, 2004)

20. T. Muneer, Build. Serv. Eng. Res. 10, 81 (1989)

21. R. Perez, R. Stewart, C. Arbogast, R. Seals, J. Scott, Sol. Energy 36, 481 (1986)

22. R. Perez, R. Seals, P. Ineichen, R. Stewart, D. Menicucci, Sol. Energy 39, 221 (1987)

23. R. Perez, P. Ineichen, R. Seals, J. Michalsky, R. Steward, Sol. Energy 44, 271 (1990)

24. H. Lund: Revised splitting procedure for calculation of direct normal radiation and diffuse radiation (Thermal Insulation Laboratory, Technical University of Denmark, Lyngby 1979) 